

\title{
Properties of Coated Controlled Release Diammonium Phosphate (DAP) Fertilizers Prepared with the Use of Bio-based Amino Oil
}

Asma Sofyane, Mohammed Lahcini, Abdellatif El Meziane, Mehdi Khouloud, Abdelmalek Dahchour, Sylvain Caillol, Mustapha Raihane

\section{To cite this version:}

Asma Sofyane, Mohammed Lahcini, Abdellatif El Meziane, Mehdi Khouloud, Abdelmalek Dahchour, et al.. Properties of Coated Controlled Release Diammonium Phosphate (DAP) Fertilizers Prepared with the Use of Bio-based Amino Oil. Journal of the American Oil Chemists' Society, 2020, 97 (7), pp.751-763. 10.1002/aocs.12360 . hal-02893146

\section{HAL Id: hal-02893146 \\ https://hal.science/hal-02893146}

Submitted on 8 Jul 2020

HAL is a multi-disciplinary open access archive for the deposit and dissemination of scientific research documents, whether they are published or not. The documents may come from teaching and research institutions in France or abroad, or from public or private research centers.
L'archive ouverte pluridisciplinaire HAL, est destinée au dépôt et à la diffusion de documents scientifiques de niveau recherche, publiés ou non, émanant des établissements d'enseignement et de recherche français ou étrangers, des laboratoires publics ou privés. 


\title{
Properties of Coated Slow-Release Diammonium Phosphate (DAP) Fertilizers Based on Biobased Amino Oil
}

\author{
Asma Sofyane, ${ }^{1}$ Mohammed Lahcini, ${ }^{1}$ Abdellatif El Meziane, ${ }^{2}$ Mehdi Khouloud, ${ }^{3}$ \\ Abdelmalek Dahchour, ${ }^{4}$ Sylvain Caillol, ${ }^{5^{*}}$ Mustapha Raihane ${ }^{1^{*}}$ \\ 1-Laboratoire de Chimie Organométallique et Macromoléculaire-Matériaux Composites. Faculté \\ des Sciences et Techniques-Université Cadi-Ayyad. 40000 Marrakech, Morocco \\ 2-Laboratoire de Biotechnologie et Bio-ingénierie Moléculaire. Équipe « Structure \& Dynamique \\ des Génomes». Faculté des Sciences et Techniques-Université Cadi-Ayyad. 40000 Marrakech, \\ Morocco \\ 3-Direction R\&D. OCP-Jorf Lasfar. B.P. 118 - 24000 El Jadida, Morocco \\ 4-Laboratoire de Chimie-DSFA - IAV-Rabat, Morocco \\ 5-ICGM, Univ Montpellier, CNRS, ENSCM, Montpellier, France
}

Abstract. In an effort to enhance the efficiency of fertilizer use and minimize their negative impact on the environment, a novel biomass-based, functional controlled-release fertilizer was use to improve nutrient use efficiency and increase crop production systems for more sustainable agriculture practices. Here, biobased amino-oil (Priamine) mixtures were proposed as an outer coating with different layers for the control of phosphorus release from diammonium Phosphate (DAP). These hydrophobic coatings conferred excellent barrier properties and flexibility to coatings. The morphological characterization of the coated fertilizer was performed by Scanning Electronic Microscopy (SEM), and Electronic Diffraction X-ray (EDX) maping, and revealed the formation of a cohesive film and a good adhesion between DAP fertilizer and coating film. The release rate of nutrients (phosphate) in water was investigated by UV-Vis spectrophotometer. The effect of coating thickness was investigated on release time and diffusion coefficient of phosphor release in distilled water. Release time increased with the coating thickness. The diffusion coefficient of nutrient release decreased with the coating thickness. Compared with uncoated granule which is totally solubilized after less than 2 hours, the P release profiles of the coated granules reached the equilibrium stage approximatively after 98 and 126 hours when the DAP is coated with only Priamine single-layer (1L) and double-layer (2L), respectively. Moreover, the strategy adopted has successfully provided a very slow release and long-term availability of nutrients sources with biobased coating oil compared to uncoated fertilizer (DAP) and therefore exhibited promising application for sustainable development of modern agriculture and circular economic.

Keywords: Fertilizer; Biobased oil; Coatings; SEM; Slow release

Corresponding authors: Mustapha. Raihane (m.raihane@uca.ma) and Sylvain Caillol (sylvain.caillol@enscm.fr) 


\section{Introduction}

The world population is expected to grow in next years and will approach 9 billion by 2050, (Alexandratos and Bruinsma, 2012; FAO, 2009) requiring a corresponding increase in crop production and food supply (c.a 40\% for cereal production (Maxmen, 2013)). Obviously, there availability of croplands is limited. To meet the food demand of the world population and to tackle the issues of food security through sustainable agriculture, much attention has been paid to fertilizers which gain prime importance in the research and development of modern agriculture practices (Majeed et al., 2015). World demand for total fertilizer nutrients $(\mathrm{N}, \mathrm{P}, \mathrm{K})$ is estimated to grow at 1.6 percent per annum from 2015 to 2019 (FAO, 2016). However, most of the commercially uncoated fertilizers, so far, are well-known for low efficiency of plant nutrients uptake due to losses on farmlands for various reasons such as runoff, leaching and volatilization (Azeem et al., 2014). These factors not only lead to financial losses but also induce risks for the environment and waste of energy related to their productions. (Entry and Sojka, 2008) Slow controlled-release fertilizer (SRF) is put forward as a new technology to solve the problem of low fertilizer use efficiency and to satisfy the increasing demand (Azeem et al., 2014; Majeed et al., 2015; Trenkel , 1997). The Association of American Plant Food Control Officials (AAPFCO) has defined the SRF as a fertilizer containing a plant nutrient in a form which delays its availability for plant uptake and use after application or which extends its availability to the plant significantly longer than a reference 'rapidly available nutrient fertilizer' such as urea, diammonium phosphate...(Fu et al., 2018)

Phosphorus (P) is an essential nutrient for life, and its management is a problem that affects global food security (Makowski et al., 2014). However, the acidity and high percentages of iron-and aluminum-based compounds in the soils reduce the efficiency of phosphate fertilizers as a result of strong phosphorus (P) fixation, which decreases the availability of this nutrient to plants (Trenkel, 1997). The demand for P fertilizers is increasing, while access to its sources is becoming uncertain due to limited resources and geopolitical concerns.(Penuelas et al., 2013) The world phosphate fertilizer demand will reach 45.8 Million tons in 2020, while it was 41.7 Million tons in 2013 (FAO, 2017), and was increased annually by 2.0 from 2015 to 2019 (FAO, 2016). However, only 10-20\% of P is taken up by the plant due to the low efficiency of soil P fertilizers (Timilsena et al., 2015). Such losses can be minimized by controlling nutrient release and maintaining a temporally homogeneous availability of phosphate at moderate levels in soil. By using P fertilizers coating, SRF has been used to increase the bioavailability of $\mathrm{P}$ fertilizers in soils (Giroto et al., 2017). The efficiency of $\mathrm{P}$ 
SRFs is usually greater than that of uncoated fertilizers (Fertahi et al., 2019; Garcia, 1997; García, 1997). More recently, an almost exponential growth in publications has been noted on the benefits of SRF to human society using polymeric material coatings (Chawakitchareon et al., 2016; Fu et al., 2018; Li et al., 2017; Majeed et al., 2015). Synthetic polymers are considered potential and attractive candidates for mineral fertilizer coatings in order to avoid fast dissolution. Some of the most commonly synthetic polymers used in the literature are polyethylene, (Salman et al., 1989) polyurethane, (Ma et al., 2013) polysulfone, (Tomaszewska and Jarosiewicz 2006), etc. Nutricote ${ }^{\circledR}$, Osmocote ${ }^{\circledR}$ and Polyon ${ }^{\circledR}$ are important manufactured synthetic polymer coatings (Trenkel, 1997). However, these polymers have shown many drawbacks, such as their high prices and their negative impact on the environment. According to Trenkel (Trenkel, 1997), the use of polymeric materials in coatings could lead to an undesirable accumulation of plastic residues of up to $50 \mathrm{~kg} / \mathrm{ha} /$ year. To reduce soil pollution and price, concentrated efforts have been put into developing environmentally friendly coating materials. These Biobased polymers (carbohydrates, lignin, agriculture residues, etc) are an alternative to petroleum-based polymers, which gained recent research interest due to their low-cost, renewability, ecosystem friendliness, availability, sustainability and degree of functionality (Azeem et al., 2014; Chen et al., 2018; Majeed et al., 2015). Indeed, there is a necessity to develop further alternatives with environ-mentally friendly coating materials and technologies for SRF (Fertahi et al., 2019). In fact, the depletion of petroleum resources, price fluctuation and negative environmental effect of petroleum-based polymer materials, biomass sources have attracted much attention to replace petroleum-based polymer materials with partially or fully bio-based polymers from abundant renewable materials (Belgacem et al., 2008). Recently, bio-based epoxy coating was prepared from the liquefied bagasse and bisphenol-A diglycidyl ether. The chemical structure and microscopic morphology of these materials were characterized by FTIR, ${ }^{1} \mathrm{H}$ NMR, SEM, and the nutrient release behaviors were also studied showing a significantly slowed nitrogen release rate (Lia et al., 2018). More recently, a fertilizer coated with triple superphosphate (TSP) fertilizer with slow-release and water retention properties was synthetized using lignin extracted from olive pomace (OP) biomass and k-carrageenan biopolymer composites to study the impact of their properties on TSP phosphorus release (Fertahi et al., 2019). The impact of plasticizer addition (PEG 2000) on lignin-k-carrageenan formulation properties and phosphorus release was also investigated. Lignin-carrageenan-PEG@TSP released only $13.51 \%$ of phosphorus after $6 \mathrm{~h}$ compared to $72 \%$ for uncoated TSP (Fertahi et al., 2019). 
Vegetable oils are excellent renewable resources, available everywhere, and cleaner than fossil energy sources, and used as a raw material for resin preparation including vegetable oilbased polyurethane (PU) (Caillol et al., 2013; Desroches et al., 2012; Lligadas et al., 2010; Petrović, 2008) and polyepoxide thermosets (Auvergne et al., 2014; Stemmelen et al., 2011). Hence, Bortoletto et al., (Bortoletto-Santos et al., 2016) studied the kinetic releases of coated urea with natural-oil-based PUs produced from soybean and castor oils and 4,4'diphenylmethane diisocyanate. These PUs exhibited a good compatibility with urea and controlled the release of nitrogen over very long periods of time (40-75 days). Transgenic soybean oil was successfully converted into bio-based PUs through chemical reactions (Liu et al., 2016). These PUs modified with hydroxyl-terminated dimethyl silicone had better performance as the coating materials for controlled-release fertilizer, by reducing the coating porosity, and increasing the water-contact angle of the coating material. Cruz et al., ( Cruz et al., 2017) proposed to use a castor oil based hydrophobic PU to control the phosphorus release from diammonium phosphate (DAP) granules. The release of $\mathrm{P}$ into water and its delivery behavior and availability into the soil was evaluated. The retention of phosphorus is governed by the percentage of used coating (ca. with $9.0 \mathrm{wt} \% \mathrm{PU}$ resulted in around $70 \%$ phosphorus release after about $500 \mathrm{~h}$ ). Novel biobased polyurethane (PU) was synthesized by using waste frying oil-based polyol (WFOP) (Liu et al., 2017) or waste palm oil-based polyol (WPOP) (Liu et al., 2018) and isocyanate for SRFs. In the case of WFOP, epoxy resin diglycidyl ether of bisphenol A (EP) was used to modify the coating in order to improve the properties of the film. The results showed that $20 \%$ EP in the coating increased the crosslinking density by $77.9 \%$, reduced the coating porosity by $28 \%$, and thus slowed the nutrient release from the PU significantly. Biobased cyclic carbonate from vegetables oils is also a promising route towards renewable and environmentally friendly Non-Isocyanate Polyurethanes (NIPU) because isocyanates are harmful and suspected to be carcinogenic (Arnold et al., 2012). In fact, the reaction between biobased carbonates oils and amines offers an interesting pathway to renewable polyhydroxyurethanes (PHUs) as new generation of polyurethane (PU) coatings (Carré et al., 2019; Moritz and Rolf, 2012). The synthesis of biobased diamine from vegetable oils was reported (Froidevaux et al., 2016). Fully biobased dimer diamines are commercially available building block (Priamine) and are suitable as hardeners for the synthesis of various biobased polymers (Dworakowska et al., 2015; Ecochard et al., 2019; Negrell et al., 2017). However, the fully or partially biobased PU, and polyepoxide coatings for SRF prepared from vegetable oils are expensive and need multistep of organics processes (modification of the vegetables oil, polymerization...), and also use 
organic solvents. Therefore, the present article proposes the use of commercial Priamine dimer diamines oil as a coating for SRF (DAP). This biobased amino oil is hydrophobic, giving excellent barrier properties to coatings and yet provides excellent flexibility and impact resistance to materials. Another important advantage of the dimer diamine is its low viscosity allowing use in high solid contents and even solvent-free formulations. However, to the best of our knowledge, the coating of fertilizers with only vegetable oils has never been reported. Therefore, this article describes for the first time, the use of amino oil (Priamine $1071{ }^{\circledR}$ ) as biobased coating for SRF. The objectives of the present work are : (i) to prepare different coatings of Priamine $1071 \AA$ with and without solvent for DAP fertilizer, (ii) the morphological characterisations of the coated DAP on the surface and cross section, (iii) the evaluation of their properties on DAP phosphorus release and the effect of the coating thickness, and finally (iv) the study of the kinetic of the $\mathrm{P}$ release in terms of diffusion coefficient and order of the reaction.

\section{Materials and Methods}

\section{Materials}

Priamine 1071® was purchased from Croda (Netherlands). Diammonium Phosphate (DAP), a granular phosphate fertilizer $\left(46 \% \mathrm{P}_{2} \mathrm{O}_{5}\right)$, is a gift from OCP Group, Morocco. Tetrahydrofuran (THF) was supplied from Aldrich and used without purification.

\section{Preparation and characterization of coating DAP fertilizers}

Granules of DAP fertilizer (50 g) were sieved to select homogeneous granules with diameters of 2-4 $\mathrm{mm}$ and then placed into a rotary drum (32 rpm). Pure Priamine and Priamine solution in THF $(1 \mathrm{wt} / 0.5 \mathrm{v})$ were used as coatings to encapsulate the fertilizers. They were poured on the surfaces of rotating DAP fertilizers using a needle glass syringe. Then, the coated fertilizers with biobased oil without and with solvent were dried at room temperature and at $60{ }^{\circ} \mathrm{C}$, respectively. This operation was repeated a second time on the coated DAP (first layer) to form a second layer. The resulting coated fertilizers were referred to as Priamine $\mathrm{xL}$ and Priamine /THF xL where $\mathrm{x}$ indicates the number of the layers.

The quality of the coatings was first evaluated by deposition onto glass slides, with selection of the conditions that resulted in the most visually homogeneous layers.

The percentage of the coating material was calculated by the following equation (1).

$$
\frac{m_{2}-m_{1}}{m_{2}}=\% \text { coating } \quad \text { Eq. } 1
$$


where $m_{2}$ and $m_{1}$ are the weights of the fertilizer after and before coating, respectively.

Infrared spectroscopy (FTIR) analyses were performed in transmittance mode with a Perkin Elmer 1725X spectrometer. The spectra were scanned within the $400-4000 \mathrm{~cm}^{-1}$ range.

Scanning Electron Microscope (SEM). The morphological characterization of uncoated and coated fertilizer (DAP) was performed by Scanning Electron Microscopy (SEM) (TESCANVEGA 3) with an accelerating voltage of $10 \mathrm{kV}$ (mode image), and coupled to an energydispersive X-ray (EDX) analysis system. Indeed, elemental mapping showing the spatial distribution of elements in the analyzed surface was also examined by SEM. For analysis, the granules were cut in half with a razor blade and fixed on a support, and the samples were dispersed on a carbon ribbon attached to the surface of a metal disc with double-sided adhesive tape. For thickness measurements of coating layers, the drawing rule option of SEM was used, and the measurements of different areas on each granule were performed.

\section{Phosphorus Release behavior of coated DAP in water}

$100 \mathrm{mg}$ of uncoated and coated DAP granules were placed in Beaker of $250 \mathrm{ml}$ of distilled water at room temperature. The system was homogenized with slight stirring continuously. After different time intervals, $0.1 \mathrm{ml}$ of different solutions were diluted 100 times to maintain the absorbance values in the calibrate rang of the spectrophotometer, and sampled for the phosphorus determination. All the release experiments were carried out in triplicate.

The phosphorus concentration was determinated following the methodology described by AFNOR T90-022 (AFNOR, 1997), involving the preparation of a mixed reagent (5 mL of 2.8 $\mathrm{g} / \mathrm{l}$ antimony and potassium tartrate solution $+50 \mathrm{~mL}$ of sulfuric acid $(15 \%)+15 \mathrm{~mL}$ of $40 \mathrm{~g} / \mathrm{l}$ ammonium molybdate $+30 \mathrm{~mL}$ of distilled water to complete the volume to $100 \mathrm{~mL}$ ) together with the ascorbic acid solution $(20 \mathrm{~g} / \mathrm{l})$.

$10 \mathrm{~mL}$ of diluted sample were added to $2 \mathrm{~mL}$ of the mixed reagent $+0.5 \mathrm{~mL}$ of ascorbic acid solution. This mixed solution was stirred for $30 \mathrm{~min}$ at room temperature, forming a blue complex which was subsequently analyzed at wavelength of $880 \mathrm{~nm}$ using an UltravioletVisible (UV-Vis) spectrophotometer (UV-2600, Shimadzu).

\section{Mathematical modeling}

Mathematical modeling is essential to gain deeper insight in understanding the release mechanism and predicting the release of nutrients through the coating material. The P release characteristics of the Priamine-coated DAP was investigated using a semi-empirical RitgerPeppas model equation 2 (Ritger and Peppas, 1987): 


$$
\frac{M_{t}}{M_{\infty}}=k t^{n} \quad \text { Eq.2 }
$$

where $M_{t}$ and $M_{\infty}$ represent the amount of nutriment released at time $t$ and at equilibrium respectively, $\mathrm{k}$ is the diffusion constant, which depends on the type of coating material, $\mathrm{t}$ is the release time and $\mathrm{n}$ is a diffusional exponent characterizing the release mechanism. (Bortoletto-Santos et al., 2016)

Diffusion coefficient $(D)$ was calculated from Equation 3:

$$
\frac{M_{t}}{M_{\infty}}=4\left(\frac{D t}{\pi l^{2}}\right)^{0.5} \quad \text { Eq.3 }
$$

where $l$ is the thickness of the composite film

\section{Results and discussion}

\section{Structure, properties and characterization of Priamine 1071}

Only one producer, Croda (Netherlands) (CRODA, 2019) has developed a new type of vegetable oil derived amine, based on its own biobased fatty acid dimer technology. In the terms of chemical structure, Priamine 1071 used in this study is a dimer fatty amines that results from the dimerization (Diels-Alder mechanism) of fatty acids followed by an amination reaction (Fig. 1) (Bonnot, 2017; Carré et al., 2019; Ecochard et al., 2019).

\section{Insert Fig.1}

The fatty acids were obtained from vegetable oil (e.g. soybean oil) by chemical conversion. Primaine 1071 is well known for its hydrophobic nature, apolar structure, high flexibility, and low $\mathrm{T}_{\mathrm{g}}$, which confers flexibility to polymer therefrom. Indeed, this amino oil is a low viscosity that can be used in systems with far less solvent or even solvent-free or low VCO formulations. Table 1 summarizes the typical characteristics of Priamine 1071.

\section{Insert Table 1}

These properties give to formulators a great flexibility as the dimer diamine functional is leading supplier of building blocks polymers with $100 \%$ renewable carbon used solely or as a cohardener and make them suitable for the synthesis of various biobased polymers such as 
sustainable coatings, adhesives, foams and engineering plastics (Aboudzadeh, 2014; Dworakowska et al., 2015; Ecochard et al., 2019; Negrell et al., 2017; Włoch et al. , 2018). In fact, Priamine has been used in developing bio-based epoxy materials and foams from microalgal oil (Negrell et al., 2017) and from epoxidized cardanol (Dworakowska et al., 2015). Aza-Michael addition on acrylated linseed oil (AELO) was performed to synthetize biobased bulk thermosets without any catalyst, Priamine 1071 was used as a cross-linker with AELO (Ecochard et al., 2019). Indeed, poly(ether-urethane-urea)s were prepared using Priamine 1071 as a chain extender (Włoch et al. , 2018). Such diamine was recently reported in polyhydroxyurethane (PHU) synthesis (Carré et al., 2019; Moritz and Rolf, 2012). These biobased polymers prepared from Priamine 1071 can be used as coatings for SRF. However, their preparations require several steps including the organic and polymerization reactions using organic solvents and therefore expensive. So we have choose to use only the Priamine oil as coating for DAP fertilizes due to it feature properties. In fact, fully Biobased organic diamine oil (Priamine 1071) with a long aliphatic chain is known for its good water repellency nature and hydrophobic nature which confers excellent sealant and protective properties. In addition, its high flexibility leads to an improved impact and crack resistance. For these reasons, Priamine 1071 has been chosen as coating to encapsulate the phosphates fertilizers for slow release of nutriments by controlling nutrient release and maintaining a temporally homogeneous availability of phosphate taken up by the plant.

In contrast to organic diamine vegetal oil, mineral oil was used to improve the physical quality of fertilizers. In fact, OCP uses mineral amino oil to encapsulate fertilizers produced by granulation technique. The acceptability of the fertilizers in the market is not only determined by their nutrient content but also by their physical quality, granular fertilizers should have appropriate mechanical strength to resist to significant fracturing and creation of excessive dust during the handling or transport and storage process to meet the market needs (Hignett, 1985). The amine value of Priamine 1071 is close to $205 \mathrm{mg} \mathrm{KOH} / \mathrm{g}$ (Table 2). Fig.S1 (In Electronic Supporting Information, ESI)) displays its IR spectrum. Two weaker bands absorption from $3250-3500 \mathrm{~cm}^{-1}$ were observed and assigned to the stretching vibration of primary amines $\left(-\mathrm{NH}_{2}\right)$. Another strong absorption bands located at 2923 and $2853 \mathrm{~cm}^{-1}$ are characteristic of the $-\mathrm{C}-\mathrm{H}$ stretching mode of aliphatic oil (Fig. S1, ESI). The absorption bands at $1575 \mathrm{~cm}^{-1}$ and in the range $1300-1580 \mathrm{~cm}^{-1}$ are attributed to the bending vibration of $\mathrm{N}-\mathrm{H}$ and C-H aliphatic bonds, respectively. In addition, the weak absorption located at 1156 $\mathrm{cm}^{-1}$ was assigned to the $\mathrm{C}-\mathrm{N}$ vibration bond. 


\section{Coated DAP Fertilizer Properties. Physicochemical and Morphological Characterization of Coated DAP Fertilizers}

Granules of DAP fertilizer were sieved to select homogeneous granules with diameters of 2-4 $\mathrm{mm}$ and then coated using Priamine ${ }^{\circledR}$ with and without solvent and by repeating the coating process 2 times. THF was used to reduce the viscosity of the oil and therefore the thickness or the percentage of the resulting coatings compared to the pure Priamine in order to study the effect of the coating thickness on the kinetic of $P$ release.

The percentages of the different coating materials calculated according to equation (1) are shown in Table 2.

\section{Insert Table 2}

Fig.2A presents a visual aspect of the coated DAP fertilizer granules compared to uncoated DAP, which clearly indicates that DAP granules were completely covered by the film coating. The visual aspect of the granules coated by Priamine 1071 were brown.

\section{Insert Fig. 2}

The hydrogen bonding between hydrogen phosphate $\left(\mathrm{HPO}_{4}{ }^{2-}\right)$ of the DAP fertilizer and the amino groups $\left(-\mathrm{NH}_{2}\right)$ of Priamine coating agent is responsible of the adhesion between both compounds. Similar results were reported by Carmon et al. (Carmona and Rodriguez, 1987) and Daud et al. (Daud et al., 2014) who studied the hydrogen bonding between phosphate and amino acid side chain, and between amino acids in protein molecules, respectively. Fig.3B shows the suggested mechanism of adhesion between DAP and Priamine $1071 \circledR$.

To understand the profile of the coating between the fertilizer and the Priamine 1071, the microscopic morphology of the surface and cross-section of uncoated DAP and their coated by both Priamine with and without solvent was observed from the scanning electron microscopy (SEM).

The SEM of the granule and the surface of uncoated and coated DAP with Priamine $1 \mathrm{~L}$ and 2L with and without solvent are shown, respectively in Fig 3.

\section{Insert Fig.3}

Fig. 3a showed that the surface of uncoated DAP presented a rough structure. When this surface was enlarged 1000 times, some pin holes and irregular morphology were obviously 
observed in Fig 3b. These cavities and cracks in the surface might be easily permeated by water molecules, then resulting in the quick release of nutrients from uncoated DAP fertilizer (Bortoletto-Santos et al., 2016; Lia et al., 2018). When the DAP granules were covered by the Priamine, the coatings showed a smoother surface than that of uncoated DAP (Fig. 3e,f) (Zhang et al. , 2016). When different amounts of Priamine coatings were used, the coating shells also exhibited different surfaces (Zhang et al. , 2016). The one with $8.97 \%$ of Priamine single layer (1L) (Fig 3f) showed a smoother than the other one coated with Priamine/THF (1L) with a small amount (5.52\% of coating) (Fig 3e). In fact, the biobased oil coating has a high flexibility resulting in an improved impact and crack resistance. Indeed, its low viscosity conferred to the shell coatings a compact structure and covered all the cavities and cracks in the surface of the uncoated DAP fertilizers when the percentage of coating increased leading to a smooth surface (Fig 3f). With its good water repellency, hydrophobic nature, Priamine brings excellent barrier properties and thus moderated the P release rate (Behin and Sadeghi, 2016).

The microscopic structures of the coated DAP were also obtained by using SEM, Fig.4 shows the cross-section micrographs SEM of the Priamine coating materials.

\section{Insert Fig.4}

As shown in Fig. 4A-B, the formation of cohesive films with different thicknesses were observed. The border and adhesion between DAP and the film coating was irregular and some times difficult to observe, most likely due to the nonspherical shape and irregular surface of the initial DAP granules (Fertahi et al., 2019; Lia et al., 2018). However, when the Priamine coating was used without solvent (Fig. 4B), the best interfacial quality was observed and appeared more compact and uniform than those of Priamine/THF (Zhang et al., 2016). This reflects the improved interaction and, therefore, the best accommodation between the DAP and the biobased oil coatings, which allowed us to obtain coatings with better adhesion (Bortoletto-Santos et al., 2016).

The thicknesses of different coated DAP granules were also determined and were found to be significantly different depending on the nature of the coating and their percentages $(1 \mathrm{~L}$ or $2 \mathrm{~L})$ For each coating, the measurements were taken at four different locations and the average thickness was calculated (Table 1) (Behin and Sadeghi, 2016; Lubkowski et al. , 2019). The thickness of different coatings based on Priamine were displayed in Fig.2S (ESI). The results showed that the average thickness is approximately $15 \mu \mathrm{m}$ and $25 \mu \mathrm{m}$ for the DAP coated by 
Priamine/THF corresponding to single-layer (1L) and double-layer (2L), respectively. However, the thickness increased when Priamine was used as coating and was closed to 65 $\mu \mathrm{m}$ and $85 \mu \mathrm{m}$ for $1 \mathrm{~L}$ and $2 \mathrm{~L}$, respectively. The thicknesses of the double coated films are approximately 1.3 and 1.6 times higher compared to the single layer of both coating films, respectively. However, the increment of the thickness was not directly proportional to the number of coatings (Ahmad et al. , 2014). When the subsequent coating was added, the first layer of polymer coat could be slightly dissolved into the second layer, which possibly explains such a condition (Ahmad et al., 2014). This observation is also supported by similar findings reported by Tomaszewska and Jarosiewicz (Tomaszewska and Jarosiewicz, 2002). The difference of the average thickness of both coatings was attributed to high viscosity of Priamine compare the lower viscosity obtained when THF solvent was used. Therefore, high thickness, compacted and good adhesion between the granule and the coating were obtained by reducing the pores sizes which became smaller as the coating percentage increased (Behin and Sadeghi, 2016) (Fig. 3).

The thickness of the coating is an important parameter that can significantly govern the nutrient release (Ahmad et al. , 2014; Tomaszewska and Jarosiewicz 2006). On the other hand, the coating percentage showed an inverse relation with the release rate of the fertilizer (Section 3.3).

The performance of Priamine coatings associated with the surface morphology was also studied using SEM coupled with the Energy Dispersive X-ray analyzer (EDX). The EDX images of uncoated and covered DAP with the single layer of Priamine coatings are illustrated in Fig. 3S. The corresponding chemical composition are also shown in Fig. 4S. Table 3 summarizes the obtained results of EDX analysis.

According to the EDXs results of uncoated DAP, the percentage of nutriment elements Nitrogen $(16.2 \%)$ and Phosphorus $(22.1 \%)$ are close to those reported by the OCP Company ( $\mathrm{N} 18 \%$, and $\mathrm{P} 20.1 \%$ (or $46 \%$ as $\left.\mathrm{P}_{2} \mathrm{O}_{5}\right)$ ) (OCP , 2019). Other elements with low percentage such as $\mathrm{S}$ and $\mathrm{Ca}$ were also obtained. The detected carbon (3.8\%) corresponds to that used during the metallization of the DAP granule in order to make the analyzed sample surface conductive and to detect it later in the SEM analysis.

Compared to uncoated DAP, the addition of Priamine coatings showed high carbon contents, with values closed to $85.5 \%$ and $77.8 \%$ when DAP were coated with Priamine with and without solvent, respectively. The measured mass fraction of carbon is related to the total mass including coating used during the SEM analysis. In addition, the percentage of $\mathrm{N}$ decreases when the DAP was covered by Priamine coatings, and is below the value of 
uncoated DAP (16.2\%). The increased carbon content on the surface of the coating is attributed to the Priamine structure as Biobased oil with carbon chains and bearing amino groups (Fig 1). The difference of carbon percentages between Priamine with and without THF (Table 3) is attributed to the percentage of coating which is higher when the Priamine was used alone (Table 1). On the other hand, the lower coating film thickness is responsible for the decreased carbon percentage in both coatings based on Priamine.

The small traces of phosphorus detected in Priamine/THF $(2.7 \%)$ could be attributed to the presence of some microspores on the surface of the Priamine/THF coating which has low percentage of coating with a thin layer of negligible thickness $(5.5 \%$; thickness: $15 \mu \mathrm{m}$, Table 1). The porosity of this formulation was responsible for the diffusion of the $\mathrm{P}$ ions to the external surface of the granule which leads to the presence of the small traces of $\mathrm{P}$ in these analyzed surfaces (Matos et al. , 2017). The absence of P in the "shell" layer of DAP coated by pure Priamine confirmed the good adhesion and absence of pores in this coating, which resulted is in good agreement with the SEM characterization.

\section{Insert Table 3}

The spatial distribution of the elements $(\mathrm{C}, \mathrm{N}, \mathrm{O}$, and $\mathrm{P})$ on the cross sections containing the interface between the DAP and Priamine coatings was investigated by the elemental mapping using EDX (Fig. 5).

\section{Insert Fig.5}

Nitrogen, oxygen and phosphorus which are the compounds of DAP granule are homogeneously distributed on its cross-section structure (Fig. 5a) (Matos et al. , 2017; Pereira et al. , 2017).

The EDX analysis has also proved that carbon from Priamine structure occurred in the layer of biobased amino oil coating (Fig. 5b and 6c) (Li et al. , 2018; Lubkowski et al. , 2019). The structure of the formed layer was homogeneous. Carbon atoms distributed regularly in the coating layer (Shell) with a good adhesion between granule fertilizer and coating. Indeed, the Priamine doesn't penetrate into the granule core.

\section{Slow release of Phosphorous from coated and uncoated DAP Fertilizers}

The Phosphorus release profiles were obtained from the procedures described by $\mathrm{Li}$ et al $(\mathrm{Li}$ et al. , 2018) and Pereira et al. (Pereira et al. , 2012). 
Considering the practical application of DAP fertilizer granules as a macronutrient fertilizer, the sustainable release behavior of the coated granules with Priamine was measured to evaluate their application prospects in agriculture. Fig. 6 displays the percentage of P released in water versus time of the four coated DAP from Priamine with different layers and the uncoated DAP at pH 7 and room temperature. The release behavior showed two stages. In fact, the release rate of coated DAP with both Priamine coatings and different layers increased rapidly from 0 to $5-10 \mathrm{~h}\left(1^{\text {st }}\right.$ stage: fast release, in insert of Fig. 6), and gradually increased from 5-10 to $90-125 \mathrm{~h} \mathrm{(} 2^{\text {sd }}$ stage: slow release), and finally reached an equilibrium (complete release) after $125-150 \mathrm{~h}$.

\section{Insert Fig. 6}

Fig. 6 shows also that the nutriment solubilisation rate in water is much slower in the case of encapsulated fertilizers (single and double layers) than for uncoated DAP. In fact, compared with uncoated granule which is totally solubilized after less than 2 hours, the P release profiles of the coated granules reached the equilibrium stage approximatively after 98 and 126 hours when the DAP is coated with only Priamine single-layer (1L) and double-layer (2L), respectively. Indeed, the time to reach maximum concentration of P release is 72 and 84 times than the corresponding uncoated DAP, when the DAP is covered with Priamine/THF $1 \mathrm{~L}$ and $2 \mathrm{~L}$, respectively, indicating significant slower $\mathrm{P}$ release properties.

The thickness of the coating is an important parameter that can significantly control nutrient release (Ahmad et al. , 2014; Jarosiewicz and Tomaszewska, 2003). Ahmad et al. (Ahmad et al. , 2014) showed that a high thickness resulted in a low phosphate release rate due to the formation of a long resistance path, which hinders the diffusion of $\mathrm{P}$. They also showed that within 10 days, coated pellets with a thickness of $63 \mu \mathrm{m}$ released $325 \mathrm{~g} \mathrm{P} / \mathrm{m}^{3}$, while the release with a thickness of $128 \mu \mathrm{m}$ was $225 \mathrm{~g} \mathrm{P} / \mathrm{m}^{3}$. Indeed, Cruz et al. (Cruz et al., 2017) reported that the DAP coated with castor polyurethane coatings with 3.0 and $4.5 \mathrm{wt} \%$ coating percentage exhibited significant delays in phosphorus release, with $80 \%$ release reached in 50 $\mathrm{h}$ for $3.0 \mathrm{wt} \%$ and $75 \mathrm{~h}$ for $4.5 \mathrm{wt} \%$.

In our case, the obtained results indicated that thicker Priamine/THF coatings can change the maximum nutrient availability toward longer periods. In fact, the maximum dissolution rate was obtained after $144 \mathrm{~h}$ for the DAP coated with $4.5 \mathrm{wt} \%$ (thickness $=15 \mu \mathrm{m}$ ), whereas, those covered with $9.95 \mathrm{wt} \%$ (thickness $=25 \mu \mathrm{m}$ ) of coating resulted in maximum release at $168 \mathrm{~h}$. Similar results were obtained when DAP is coated with only Priamine with single (8.9 $\%, 65 \mu \mathrm{m})$ and double layers $(14.2 \%, 85 \mu \mathrm{m})$. This fact is associated with the reduction in the 
number of pinholes which are the primary path for P release from coated DAP (Behin and Sadeghi, 2016).

In order to investigate the nutrients release mechanism from the coated DAP granules in water, the $n$ and $k$ values are estimated from the linear regression of $\log \left(\frac{M_{t}}{M_{\infty}}\right)$ versus $\log (t)$ for the uncoated DAP and encapsulated DAP with amino-oil /solvent and without solvent using the Ritger-Peppas model (Eq 2) (Ritger and Peppas, 1987). This model can be used to describe the release rate of fertilizers from polymeric devices. In the case of $n \leq 0.5$, the nutrient release mechanism is Fickian diffusion. When $n=1$, the transport mechanism dominates, leading to zero-order release. If the $\mathrm{n}$ value is ranging between 0.5 and 1 , the nutrient release behavior can be regarded as the superposition of the above two phenomena, which is called anomalous transport driven by a combination of diffusion and relaxation of the coating matrix (Xu et al. , 2014). For $\mathrm{n}$ values $>1$, it's assumed that this indicates a strong influence of the coating on retarding the release, which is gradually allowing the diffusion (accelerating the process) by opening pores or degrading the structure (Bortoletto-Santos et al., 2016; Cruz et al., 2017; Lubkowski et al. , 2019).

The $\mathrm{k}, \mathrm{n}$, and $\mathrm{D}$ values for $\mathrm{P}$ release from the two Priamine coatings (single and double layers) corresponding to the $1^{\text {st }}$ and $2^{\text {sd }}$ release stages were obtained, and the resulting data are summarized in Table 4 . The correlation coefficient $\left(\mathrm{R}^{2}\right)$ was $>0.90$ in all cases.

\section{Insert Table 4}

For the fast release $\left(1^{\text {st }}\right.$ stage), table 1 showed an exponent (n) greater than 1 for both Priamine coating (except for the uncoated DAP, $\mathrm{n} \approx 0.5$ ), indicating that the diffusion occured from the pores in the coating, which gradually become modified by the diffusion process itself. Thus, this behavior is called non-Fickian diffusion process (Cruz et al., 2017).

Controlled release of nitrogen and phosphorus from the coated materials with polyurethane coatings from castor oil reported similar behavior where the $\mathrm{n}$ values are above unity (Bortoletto-Santos et al., 2016; Cruz et al., 2017). However, for the slow release related to the second stage, the $\mathrm{n}$ values of the diffusion exponent were ranged between 0.09 and 0.25 ( $<<0.5$, Table 4) indicating that the mechanism release is a Fickian diffusion process (i.e., a typical diffusion trough coating thickness (Bortoletto-Santos et al., 2016; Li et al. , 2019).

It is also noticed that the values of $\mathrm{k}$ release factor increased when the percentage of coating decreased and vice versa. For example, when the DAP was coated with Priamine /THF, the k value of fast release (Table 4) decreased from $12.3710^{-2}$ to $6.9510^{-2} \mathrm{~h}^{-1}$ while the percentage 
of coating increased from $5.52(1 \mathrm{~L})$ to $9.95 \%$ (2L), respectively. The same result was also confirmed for the slow release stage using both Priamine coatings (Table 4). This is attesting that the thickness of the coating is an important parameter that can significantly govern the nutrient release. Indeed, for the faster release $\mathrm{k}($ Priamine/THF $)>\mathrm{k}$ (Priamine) for both coating thickness attesting that the P release is slower when the DAP was coated by Priamine. In fact, after $3 \mathrm{~h}$ of immersion in water, the \% P release was close to $10 \%$ for Priamine (2L) and $30 \%$ for Priamine/THF (2L) (Fig. 6, in insert).

Hence, the diffusion coefficient estimation (D) of the nutrient release can be used as a design tool for the development of new controlled release fertilizers with known and desired release characteristics (Ni et al. , 2011). The data on diffusion coefficients of the $\mathrm{P}$ nutrient release from different Priamine samples for different coating thicknesses ( $1 \mathrm{~L}$ and $2 \mathrm{~L}$ ) is given in Table 4 . For the fast release $\left(1^{\text {st }}\right.$ stage), the transport of nutrient through the hydrophobic biobased amino oil coatings is expected to follow the non-Fickian or anomalous diffusional transport according to the diffusion exponent $\mathrm{n}$. In this case, the diffusion coefficient decreased with the increase in coating thickness when the DAP was coated with Priamine, the diffusion coefficient (D) was calculated to be $13.96 \times 10^{-11}$ to $7.55 \times 10^{-11} \mathrm{~cm}^{2} / \mathrm{s}$ for Priamine single-layer $(8.97 \%, 65.00 \mu \mathrm{m})$ and double-layer $(14.14 \%, 85.00 \mu \mathrm{m})$ coated fertilizer granules, respectively (Azeem et al. , 2016). Indeed, for the slow release (Table 4), it's noticed that the diffusion coefficient for Priamine single-layer $\left(11.60 \times 10^{-11} \mathrm{~cm}^{2} / \mathrm{s}\right)$ was higher than those of double-layer $\left(10.27 \times 10^{-11} \mathrm{~cm}^{2} / \mathrm{s}\right)$ explaining that the maximum concentration of $\mathrm{P}$ release was reached in 98 and $126 \mathrm{~h}$ when the DAP was covered with Priamine/THF $1 \mathrm{~L}$ and 2L, respectively. Majeed et al. (Majeed et al. , 2016) noticed that the coefficient D value reduced with increasing the amount of lignin in biodegraded composite films, from $2.1 \times 10^{-7}$ to $1.50 \times 10^{-7} \mathrm{~cm}^{2} / \mathrm{s}$ for urea cross-linked starch film reinforced with 5 and 20 (\%wt. / \%wt.) of lignin. respectively.

The release behaviors were very complex and depended on the nature and amount of polymer matrix, cross-link density, polymer network behavior and elasticity, porosity (imperfections in the coating surface), thickness of the coating layer, water uptake, and coating preparation method (Fertahi et al., 2019). For these reasons, it is very difficult to compare different studies in the literature such polyurethane based on fatty oils.

It should be noted that this full immersion experiment in water is very aggressive and may not correspond to real conditions in the field, where the moisture level is limited by the water retention capacity of the soil. So, in the future, these biobased oil mixtures will be tested to evaluate their slow phosphorus release properties under natural aerobic soil condition. 


\section{Conclusion}

A novel bio-based amino oil as low-cost and renewable resources was used as a green coating material for slow phosphorus release of diammonium phosphate (DAP) fertilizer to get slowed and continuous delivery of nutrients compared to uncoated DAP. Depending on the amount and the nature of the components of the coating materials (amino-oil and solvent), the obtained materials differed from each other regarding color, layer thickness. The hydrogen bonding between hydrogen phosphate $\left(\mathrm{HPO}_{4}{ }^{2-}\right)$ of the DAP fertilizer and the amino groups $\left(-\mathrm{NH}_{2}\right)$ of Priamine coating agent is responsible of the adhesion between both compounds.

The morphological characterization of the coated fertilizer on the surface and cross section was performed by Scanning Electronic Microscopy (SEM), and Electronic Diffraction X-ray (EDX) maping, and revealed the formation of a cohesive film and a good adhesion between DAP fertilizer and the Priamine coatings.

Compared with uncoated DAP granule which is totally solubilized after less than 2 hours, the $\mathrm{P}$ release profiles of the coated granules with Priamine/THF reached the equilibrium stage approximatively after 144 and $168 \mathrm{~h}$ when the coating thickness is 5.52 (single-layer (1L) and $9.95 \%$ (double-layer), respectively. The kinetic parameters (order reaction, diffusion coefficient) were also calculated and the relation structure and thickness of coatings- kinetic $\mathrm{P}$ releases was studied. These environment-friendly biobased amino oils with superior controlled release properties could be especially useful in sustainable agricultural applications.

\section{Acknowledgements}

The Authors would like to acknowledge the support through the R\&D Initiative -Call project APPHOS-sponsored by OCP (OCP Foundation, R\&D OCP, Mohammed VI Polytechnic University, National Centre of Scientific and technical Research CNRST, Ministry of Higher Education, Scientific Research and Professional Training of Morocco MESRSFC) project IDVAL-RAI-01/2017. The authors thank also Dr ABLOUH El-houssaine for the SEM and EXD-Maping analysis performed in CAC of Cadi-Ayyad University.

\section{Conflict of Interest}

The authors declare that they have no conflict of interest. 


\section{$\underline{\text { References }}$}

Aboudzadeh, A., Fernandez, M., Munoz, M. E., Santamaria, A., \& Mecerreyes, D. (2014) Ionic Supramolecular Networks Fully Based on Chemicals Coming from Renewable Sources. Macromol. Rapid Commun, 35:460-465. https://doi.org/10.1002/marc.201300732.

AFNOR, (1997). Recueil de normes françaises eau, méthodes d'essai, 2 ème édition.

Ahmad, N. N. R., Fernando, W. J. N. \& Uzir, M. H. (2014) Parametric evaluation using mechanistic model for release rate of phosphate ions from chitosan- coated phosphorus fertiliser pellets. Biosystems Engineering, 129:78-86.

http://dx.doi.org/10.1016/j.biosystemseng.2014.09.015.

Alexandratos, N., and Bruinsma, J. (2012) World Agriculture Towards 2030 / 2050: The 2012 Revision. ESA Working paper No. 12-03. Rome, FAO.

Arnold, S. M., Collins, M. A., Graham, C., Jolly, A. T., Parod, R. J., Poole, A., Schupp, T., Shiotsuka, R.N., \& Woolhiser, M.R. (2012) Risk assessment for consumer exposure to toluene diisocyanate (TDI ) derived from polyurethane flexible foam. Regulatory Toxicology and Pharmacology, 64:504-515. http://dx.doi.org/10.1016/j.yrtph.2012.07.006.

Auvergne, R., Caillol, S., David, G., Boutevin, B., \& Pascault, J. P. (2014) Biobased Thermosetting Epoxy: Present and Future. Chemical Reviews, 114:1082-1115. https://doi.org/10.1021/cr3001274.

Azeem, B., KuShaari, K., Man, Z. B., Basit, A., \& Thanh, T. H. (2014) Review on materials $\&$ methods to produce controlled release coated urea fertilizer. Journal of Controlled Release, 181:11-21. https:// doi.org/10.1016/j.jconrel.2014.02.020.

Azeem, B., Kushaari, K., \& Man, Z. (2016) Effect of Coating Thickness on Release Characteristics of Controlled Release Urea Produced in Fluidized Bed Using Waterborne Starch Biopolymer as Coating Material. Procedia Engineering, 148:282-289. https://doi.org/10.1016/j.proeng.2016.06.615.

Behin, J. and Sadeghi, N. (2016) Utilization of waste lignin to prepare controlled-slow release urea. International Journal of Recycling of Organic Waste in Agriculture, 5:289-299. https://doi.org/10.1007/s40093-016-0139-1.

Belgacem, M. N. and Gandini, A. (2008). Monomers, Polymers and Composites from Renewable Resources ( $1^{\text {st }}$ edition).

Bonnot, L., (2017) Phd thesis: Valorisation du divinylglycol (DVG), dérivé du glycérol, pour la synthèse de polymères originaux. Bordeaux University (France).

Bortoletto-Santos, R., Ribeiro, C. \& Polito, W. L. (2016) Controlled release of nitrogensource fertilizers by natural-oil-based poly(urethane) coatings: The kinetic aspects of urea release. Journal of Applied Polymer Science, 133:1-8. https://doi.org/10.1002/app.43790.

Caillol, S., Desroches, M., Carlotti, S., Auvergne R., \& Boutevin, B. (2013) Synthesis of new polyurethanes from vegetable oil by thiol-ene coupling. Green Materials, 1:16-26. https://doi.org/10.1680/gmat.12.00001.

Carmona, P., and Rodriguez, M. L. (1987) Hydrogen bonds between protein side chains and phosphates and their role in biological calcification. Biophysical Chemistry, 28:161-167. https://doi.org/10.1016/0301-4622(87)80085-6. Carmona, P., and Rodriguez, M. L. (1986) Hydrogen bonds between phosphate and amino acid side chains. Journal of Molecular Structure, 143:365-368. https://doi.org/10.1016/0022-2860(86)85278-4.

Carré, C., Ecochard, Y., Caillol, S., \& Averous, L. (2019) From the Synthesis of Biobased Cyclic Carbonate to Polyhydroxyurethanes : A Promising Route towards Renewable NonIsocyanate Polyurethanes. Journal of Polymer Science Part A: Polymer Chemistry, 12:122. https://doi.org/10.1002/cssc.201900737.

Chawakitchareon, P., Anuwattana, R., \& Buates, J. (2016) Production of Slow Release Fertilizer from Waste Materials. Advanced Materials, 175:129-137. http://dx.doi.org/10.1007/978-3-319-26324-3

Chen, J., Lü, S., Zhang, Z., Zhao, X., Li, X., Ning, P., \& Liu, M. (2018) Science of the Total 
Environment Environmentally friendly fertilizers : A review of materials used and their effects on the environment. Science of the Total Environment, 613-614:829-839. https://doi.org/10.1016/j.scitotenv.2017.09.186.

CRODA(2019).http://www.crodacoatingsandpolymers.com/home.aspx?s=139\&r=669\&p=33 25. accessed 10/25/2019.

Cruz, D. F., Bortoletto-Santos, R., Guimaraẽs, G. G. F., Polito, W. L., \& Ribeiro, C. (2017) Role of Polymeric Coating on the Phosphate Availability as a Fertilizer: Insight from Phosphate Release by Castor Polyurethane Coatings. Journal of Agricultural and Food Chemistry, 65:5890-5895. https://doi.org/10.1021/acs.jafc.7b01686.

Daud, N. S., Ghazi, T., \& Ahamad, I. S. (2014) Wheat germ as natural coagulant for treatement of Palm oil Mill Effluent. Int. J. Chem and Envir Eng, 5:111-115.

Desroches, M., Escouvois, M., Auvergne, R., Caillol S., \& Boutevin, B. (2012) From vegetable oils to polyurethanes, synthetic routes to polyols and main industrial products. Polymer Reviews. 2012, 52:38-79. https://doi.org/10.1080/15583724.2011.640443

Dworakowska, S., Cornille, A., Bogdal, D., Boutevin, B., \& Caillol, S. (2015) Formulation of bio-based epoxy foams from epoxidized cardanol and vegetable oil amine. European Journal of Lipid Science and Technology, 117:1893-1902, pp. 1893-1902. https://doi.org/10.1002/ejlt.201500232

Ecochard, Y., Boutevin, B. \& Caillol, S. (2019) Linseed Oil-Based Thermosets by AzaMichael Polymerization. European Journal of Lipid Science and Technology, 122:1-9. https://doi.org/10.1002/ejlt.201900145

Entry, JA., and Sojka, R. (2008) Matrix based fertilizers reduce nitrogen and phosphorus leaching in three soils. Journal of Environmental Management, 87:364-372. https://doi.org/10.1016/j.jenvman.2007.01.044.

FAO (2009). Global agriculture towards 2050 in High Level Expert Forum « How to feed the world in $2050 »$. Summary report Food and Agriculture Organization of the United Nations, Rome 12-13 October 2009.

FAO (2017) World fertilizer trends and outlook to 2020. Food and Agriculture Organization of United Nations (FAO), Rome, 2017.

FAO (2016). World fertilizer trends and outlook to 2019. Summary report, Food and Agriculture Organization of the United Nations, Rome 2016.

Fertahi, S., Bertrand, I., Amjoud, M., Oukarroum, A., Arji, M., \& Barakat. A. (2019) Properties of Coated Slow-Release Triple Superphosphate (TSP) Fertilizers Based on Lignin and Carrageenan Formulations. ACS Sustainable Chemistry \& Engineering. 7:10371-10382. https://doi.org/10.1021/acssuschemeng.9b00433.

Froidevaux, V., Negrell, C., Caillol, S., Pascault, J. P., \& Boutevin, B. (2016) Biobased Amines : From Synthesis to Polymers ; Present and Future. Chem. Rev., 116:14181-14224 https://doi.org/10.1021/acs.chemrev.6b00486.

Fu, J., Wang, C., Chen, X., Huang, Z., Huang, Z., \& Chen, D. (2018) Communications in Soil Science and Plant Analysis Classification research and types of slow controlled release fertilizers ( SRFs ) used. Communications in Soil Science and Plant Analysis, 49: 22192230. https://doi.org/10.1080/00103624.2018.1499757

Garcia, M. C, Diez, J. A., Vallejo, A., Garcia, L., \& Cartagena, M. C. (1997) Effect of Applying Soluble and Coated Phosphate Fertilizers on Phosphate Availability in Calcareous Soils and on P Absorption by a Rye-Grass Crop. J. Agric. Food Chem, 45:1931-1936. https://doi.org/10.1021/jf960600a

García, M. C., Vallejo, A., García, L., \& Cartagena, M. C. (1997) Manufacture and Evaluation of Coated Triple Superphosphate. Ind. Eng. Chem. Res.36:869-873, pp. 869873. https://doi.org/10.1021/ie960153o.

Giroto, A.S., Guimaraẽs, G.G.F., Foschini, M., \& Ribeiro, C. (2017) Role of Slow-Release Nanocomposite Fertilizers on Nitrogen and Phosphate Availability in Soil. Nature 
Publishing Group, 7:46032. https://doi.org/10.1038/srep46032.

Hignett, T. P. (1985) Physical and Chemical Properties of Fertilizers and Methods for their Determination. Springer Science+Business Media Dordrecht, Netherlands.

Hinsinger, P. (2001) Bioavailability of soil inorganic P in the rhizosphere as affected by rootinduced chemical changes, Plant Soil, 237:173-195. http://dx.doi.org/10.1023/A:1013351617532.

Jarosiewicz, A., and Tomaszewska, M. (2003) Controlled-Release NPK Fertilizer Encapsulated by Polymeric. J. Agric. Food Chem, 51:413-417, pp. 413-417. https://doi.org/10.1021/jf020800o.

Lia, Y., Jiaa, C., Zhanga, X., Jianga, Y., Zhangc, M., Lua, P., \& Chenb, H. (2018) Progress in Organic Coatings Synthesis and performance of bio-based epoxy coated urea as controlled release fertilizer. Progress in Organic Coatings, 119:50-56, https://doi.org/10.1016/j.porgcoat.2018.02.013.

Ligadas, G. L., Ronda, J. C., Galia, M., \& Cadiz V. (2010) Plant Oils as Platform Chemicals for Polyurethane Synthesis: Current State-of-the-Art. Biomacromolecules, 11:2825-2835. https://doi.org/10.1021/bm100839x

Liu, J., Yang, Y., Gao, B., Li, C. Y., \& Xie, J. (2018) Bio-based elastic polyurethane for controlled-release urea fertilizer: Fabrication, properties, swelling and nitrogen release characteristics, Journal of Cleaner Production, 209: 528-537. https://doi.org/10.1016/j.jclepro.2018.10.263.

Liu, X., Yang, Y., Gao, B., Li, Y., \& Wan, Y. (2017) Environmentally Friendly Slow-Release Urea Fertilizers Based on Waste Frying Oil for Sustained Nutrient Release. $A C S$ Sustainable Chem. Eng., 5:6036-6045. https://doi.org/10.1021/acssuschemeng.7b00882.

Liu, X., Yang, Y., Gao, B., \& Li, Y. (2016) Organic silicone-modified transgenic soybean oil as bio-based coating material for controlled-release urea fertilizers. Journal of Applied Polymer Science, 133:1-8. https://doi.org/10.1002/app.44097.

Li, T., Gao, B., Tong, Z., Yang, Y., \& Li, Y. (2019) Chitosan and Graphene Oxide Nanocomposites as Coatings for Controlled-Release Fertilizer. Water, Air, \& Soil Pollution. 230:146. https://doi.org/10.1007/s11270-019-4173-2.

Li, T., Lü, S., Ji, Y., Qi, T., \& Liu, M. (2018) A biodegradable Fe-fertilizer with high mechanical property and sustainable release for potential agriculture and horticulture applications. New journal of chemistry, 42:19129-19136. https://doi.org/10.1039/c8nj04381g.

Li, Y., Sun, Y., Liao, S., Zou, G., Zhao, T., Chen, Y., Yang, J., \& Zhang. L. (2017) Effects of two slow-release nitrogen fertilizers and irrigation on yield, quality, and water-fertilizer productivity of greenhouse tomato. Agricultural Water Management, 186:139-146. https://doi.org/10.1016/j.agwat.2017.02.006.

Lubkowski, K., Smorowska, A., Sawicka, M., Wróblewska, E., Dzienisz, A., Kowalska, M., \& Sadłowski, M. (2019) Ethylcellulose as a coating material in controlled-release fertilizers. Journal of Chemical Technology, 21:52-58. https://doi.org/10.2478/pjct-20190010

Majeed, Z., Mansor, N., Man, Z., \& Wahid, S. A. (2016) Lignin reinforcement of ureacrosslinked starch films for reduction of starch biodegradability to improve slow nitrogen release properties under natural aerobic soil condition. E-Polymers, 16:159-170. https://doi.org/10.1515/epoly-2015-0231.

Majeed, Z., Ramli, N. K., Mansor, N., \& Man, Z. (2015) A comprehensive review on biodegradable polymers and their blends used in controlled- release fertilizer processes. Reviews in Chemical Engineering, 31:69-95. https://doi.org/10.1515/revce-2014-0021.

Makowski, D., Nesme, T., Papy, F., \& Dore, T. (2014) Global Agronomy, a New Field of Research. A Review. Agronomy for Sustainable Development, 34(2):293-30. https://doi.org/10.1007/s13593-013-0179-0. 
Matos, M., Mattos, B. D., Tardy, B. L., Rojas, O. J., \& Magalhaẽs, W. L. E. (2017) Use of biogenic silica in porous alginate matrices for sustainable fertilization with tailored nutrient. ACS Sustainable Chem., 6:2716-2723. https://doi.org/10.1021/acssuschemeng.7b04331.

Maxmen, A. (2013) Crop pests: under attack. Nature, 501:S15-S17. https://doi.org/10.1038 $1501 \mathrm{~S} 15 \mathrm{a}$

Ma, Z., Jia, X., Hu, J., Liu, Z., Wang, H., \& Zhou, F. (2013) Mussel-Inspired Thermosensitive Polydopamine- graf $\mathrm{t}$ - Poly( $\mathrm{N}$ - isopropylacrylamide) Coating for Controlled-Release Fertilizer. J. Agric. Food Chem., 61:12232-12237. https://doi.org/10.1021/jf4038826

Moritz, B., and Rolf, M. (2012) Green Chemistry Linseed and soybean oil-based polyurethanes prepared via the non-isocyanate route and catalytic carbon dioxide conversion. Green Chemistry, 14:483-489. https://doi.org/10.1039/c2gc16230j.

Negrell, C., Cornille, A., Nascimiento, P. A., Robin, J. J., \& Caillol, S. (2017) New bio-based epoxy materials and foams from microalgal oil. European Journal of Lipid Science and Technology, 119:1600214-1600227. https://doi.org/10.1002/ejlt.201600214.

Ni, Boli, Liu, M., Lü, S., Xie, L., \& Wang, Y. (2011) Environmentally friendly slow-release nitrogen fertilizer, J. Agric. Food Chem., 59:10169-10175. https://doi.org/10.1021/jf202131z.

OCP (2019). https://www.ocpgroup.ma/sites/default/files/2016-10/OCP_VAr-VFr_def_22-04 15_C_9.pdf. accessed 01/31/2020.

Penuelas, J., Poulter, B., Sardans, J., Ciais, P., Van Der Velde, M., Bopp, L., Boucher, O., Godderis, Y., Hinsinger, P., Llusia, J., Nardin, E., Vicca, S., Obersteiner, M., \& Janssens, IA. (2013) Human-Induced Nitrogen-phosphorus Imbalances Alter Natural and Managed Ecosystems across the Globe. Nat. Commun., 4:2934. https://doi.org/10.1038/ncomms3934.

Pereira, E. I. et al. (2012) Urea - Montmorillonite-Extruded Nanocomposites: A Novel SlowRelease Material. Journal of Agricultural and Food Chemistry, 60:5267-5272. https://doi.org/10.1021/jf3001229.

Pereira, E. I., Nogueira, A. R. A., Cruz, C. C. T., Guimaraẽs, G. G. F., Foschini, M. M., Bernardi, A. C. C., \& Ribeiro, C. (2017) Controlled Urea Release Employing Nanocomposites Increases the Efficiency of Nitrogen Use by Forage. ACS Sustainable Chem. Eng., 5:9993-10001. https://doi.org/10.1021/acssuschemeng.7b01919.

Petrović, Z. S. (2008) Polyurethanes from Vegetable Oils Polyurethanes from Vegetable Oils. Polymer Reviews, 48:37-41. https://doi.org/10.1080/15583720701834224.

Ritger, P. L. and Peppas, N. A. (1987) A simple equation for description of solute release. Journal of Controlled Release, 5:23-36. https://doi.org/10.1016/0168-3659(87)90034-4

Salman, O. A., Hovakeemian, G. \& Khraishi, N. (1989) Polyethylene-Coated Urea. 2. Urea Release As Affected by Coating Material, Soil Type, and Temperature. Ind. Eng. Chem. Res., 28:633-638. https://doi.org/10.1021/ie00089a022

Stemmelen, M., Pessel, F., Lapinte, V., Caillol, S., Habas J. P., \& Robin, J. J. (2011) A Fully Biobased Epoxy Resin from Vegetable Oils : From the Synthesis of the Precursors by Thiol-ene Reaction to the Study of the Final Material. Journal of Polymer Science Part A: Polymer Chemistry, 49:2434-2444. https://doi.org/10.1002/pola.24674.

Timilsena, Y. P., Adhikari, R., Casey, P., Muster, T., Gill, H., \& Adhikari, B. (2015) Enhanced efficiency fertilisers: a review of formulation and nutrient release patterns. Society of Chemical Industry, 95(6). https://doi.org/10.1002/jsfa.6812.

Tomaszewska, M., and Jarosiewicz, A. (2002) Use of polysulfone in controlled-release NPK fertilizer formulations. Journal of Agricultural and Food Chemistry, 50:4634-4639. https://doi.org/10.1021/jf0116808

Tomaszewska, M. and Jarosiewicz, A. (2006) Encapsulation of mineral fertilizer by polysulfone using a spraying method. Desalination, 198:346-352. 
https://doi.org/10.1016/j.desal.2006.01.032.

Trenkel, M. E. (1997) Use Efficiency Controlled-Release and Stabilized Fertilizers in Agriculture. the International Fertilizer Industry Association, Paris, December 1997.

Włoch, M., Datta, J. \& Błażek, K. (2018) The Effect of High Molecular Weight Bio-based Diamine Derivative of Dimerized Fatty Acids Obtained from Vegetable Oils on the Structure , Morphology and Selected Properties of Poly( ether-urethane-urea )s. Journal of Polymers and the Environment, 26:1592-1604. https://doi.org/10.1007/s10924-017-10595.

Wang, X., Shaoyu, L., Chunmei, G., Xiubin, Xu., Yi, W., Xiao, B., Chen, F., Nannan, G., Mingzhu, L., \& Lan, W. (2014) Biomass-based multifunctional fertilizer system featuring controlled-release nutrient, waterretention and amelioration of soil. RSC Advances, 4:18382-18390. https://doi.org/10.1039/C4RA00207E.

Zhang, S., Yang, Y., Gao, B., Wan, Y., Li, Y. C., \& Zhao, C. (2016) Bio-based Interpenetrating Network Polymer Composites from Locust Sawdust as Coating Material for Environmentally Friendly Controlled-Release Urea Fertilizers. J. Agric. Food Chem., 64:5692-5700. https://doi.org/10.1021/acs.jafc.6b01688. 


\section{Figures Captions}

Fig. 1 Idealized structure of Priamine $1071{ }^{\circledR}$ (Ecochard et al., 2019).

Fig.2 (A) Real image of (a) uncoated DAP, and coated DAP with Priamine (b) single-layer, (c) double-layer. (B) Proposed physical hydrogen bonding between DAP fertilizer and Priamine coating.

Fig.3 SEM images of the granule (A) and of the surface (B) with different magnitudes: uncoated DAP (a, d), and coated DAP single layer (b, e) with Priamine/THF and (c, f) Pure Priamine.

Fig.4 SEM the cross-section section containing the interface between the DAP and Priamine coatings: (A) with THF and (B) without THF for different layers (1L and 2L).

Fig.5 Electron image and chemical mapping of Carbone, Nitrogen, Oxygen and Phosphorus obtained from the cross-section of uncoated DAP (a), DAP coated Priamine/Solvent 1L (b) and DAP coated Priamine 1L (c) (Bar scale: $50 \mu \mathrm{m}$ ).

Fig.6 Release rate of $\mathrm{P}$ in distilled water from uncoated DAP, and coated DAP with singlelayer and DAP coated double-layer of Priamine /THF and Priamine. 


\section{$\underline{\text { Tables Captions }}$}

Table 1 The typical characteristics of Priamine 1071.

Table 2. Percentage of coating materials with different layers (L).

Table 3. Elemental composition from EDX analysis on the surface of uncoated and coated DAP Fertilizer.

Table 4. Calculated kinetic parameters according to the Ritger-Peppas Model (released exponent (n), release factor (k) and diffusion coefficient (D)) for the two stages. 